UCRL-JC-121400

PREPRINT

\title{
Mechanism of Ductile Rupture in the Al/Sapphire System Elucidated Using X-Ray Tomographic Microscopy
}

\author{
W.E. King \\ G.H. Cämpbell \\ D.L. Haupt \\ J.H. Kinney \\ R.A. Riddle \\ W.L. Wien
}

This paper was prepared for submittal to

Fall Meeting of the Materials Research Society

Boston, MA

November 27-December 2, 1995

December 18, 1995

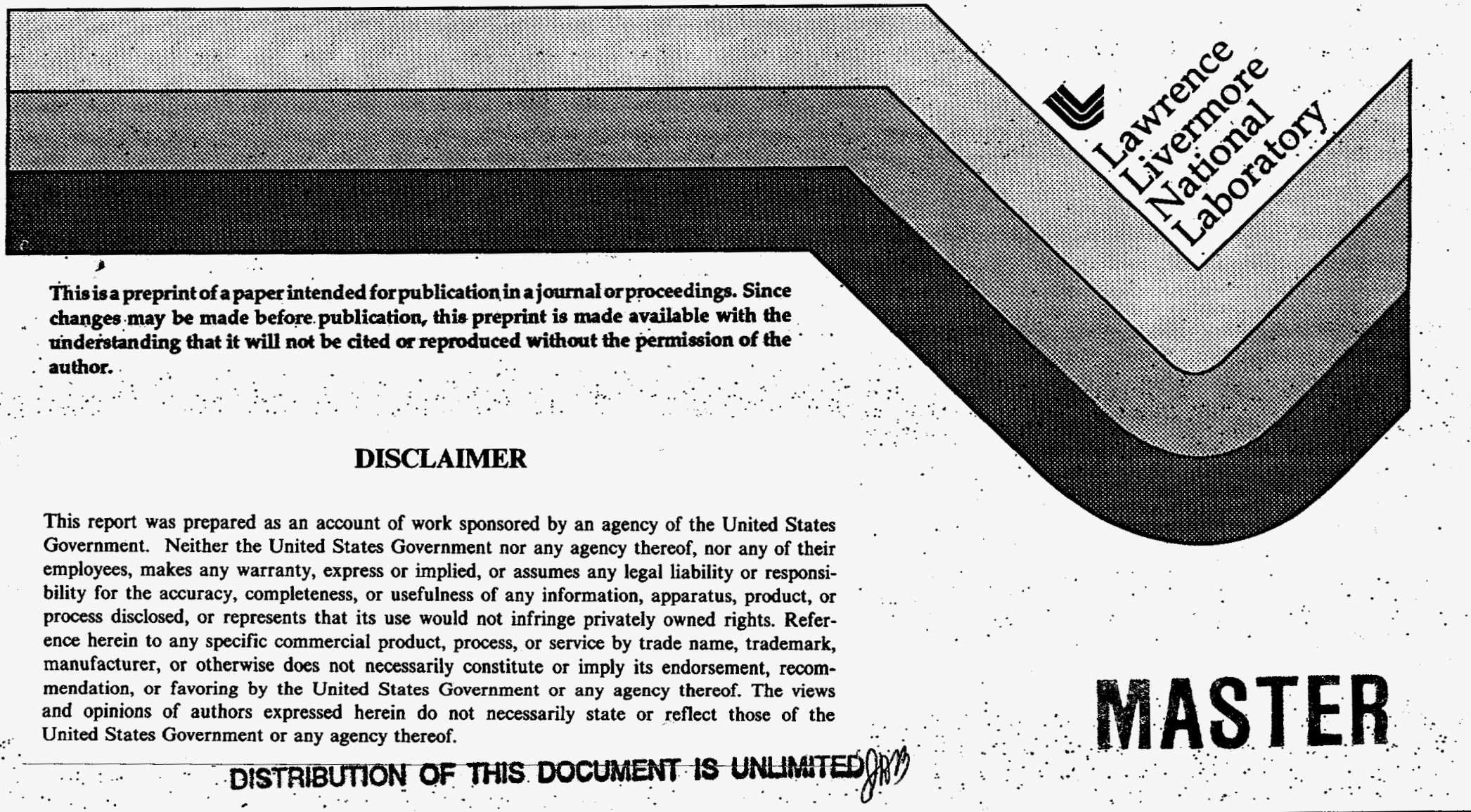




\section{DISCLAMERR}

Portions of this document may be illegible in electronic image products. Images are produced from the best available original document. 


\title{
MECHANISM OF DUCTME RUPTURE IN THE AL/SAPPHIRE SYSTEM ELUCI- DATED USING X-RAY TÖMOGRAPHIC MICROSCOPY
}

\author{
WAYNE E KING*, GEOFFREY H. CAMPBELL*, DAVID L. HAUPT**, \\ JOHN H. KINNEY*, ROBERT A. RIDDLE**, AND WALTERL. WIEN* \\ *Chemistry and Materials: Science Department \\ * Mechanical Engineering Department \\ University of California, Lawrence Livermore National Laboratory, Livermore, CA $94551-9.900$
}

\section{ABȘTRACT}

The fracture of a thin metal foil constrained between alumina or sapphire blocks hạs been studied by a number of investigators. The systems that have been investigated include $\mathrm{Al}$ [1,2], $\mathrm{Au}$ [3], $\mathrm{Nb}$ [4], and $\mathrm{Cu}$ [5]. Except for $\mathrm{Al} / \mathrm{Al}_{2} \mathrm{O}_{3}$ interfaces, these systems exhibit a common fracture mechanism: pores form at the metal/ceramic interface several foil thicknesses ahead of the crack which, under increasing load, grow and link with the initial crack. This mechanism leaves metal on one side of the fracture surface and clean ceramic on the other. This has not been the observation in $\mathrm{Al} / \mathrm{Al}_{2} \mathrm{O}_{3}$ bonds where at appropriate thicknesses of $\mathrm{Al}$, the fracture appears to proceed as a ductile rupture through the metal.

$\therefore$ The failure of sandwich geometry samples has been considered in several published models, e.g., $[6 ; 7]$. The predictions of these models depend on the micromechanic mechanism of crack extension. For example, Varias et al. proposed four possible fracture mechanisms: (i) near-tip void growth at second phase particles or interfacial pores and coalescence with the main crack, (ii) high-triaxiality cavitation, i.e., nucleation and rapid void growth at highly stressed sites at distances of several layer thicknesses from the crack tip, (iii) interfacial debonding at the site of highest normal interfacial traction, and (iv) cleavage fracture of the ceramic. Competition among the operative mechanisms determines which path will be favored.

This paper addresses the question of why the fracture of the $\mathrm{Al} / \mathrm{Al}_{2} \mathrm{O}_{3}$ system appears to be different from other systems by probing the fracture mechanism using $\mathrm{X}$-ray tomographic microscopy. (XTM): We have experimentally duplicated the simplified geometry of the micromechanics models and subjected the specimens.to.a well defined stress state in bending. The bend tests were interrupted and XTM. was performed to reveal the mechanism of crack extension.

\section{EXPERIMENT}

The system of pure aluminum bonded to sapphire exhibits low X-ray absorption, chemical compatibility, and a tendency to rupture in a ductile manner. Sapphire avoids the problems associated with grain pull-out and porosity present in polycrystalline alumina: The sapphire was purchased as cylinders of $16 \mathrm{~mm}$ diameter by $20 \mathrm{~mm}$ height with faces polished parallel to $(0001) \pm 1^{\circ}$ and $\lambda / 10(\lambda \approx 550 \mathrm{~nm})$ flatness. The aluminum foil was purchased as $99.999 \%$ pure and $50 \mu \mathrm{m}$ thick. The foil was laser cut into disks of 19 mim diamèter. A support ring assembly. made of commercially pure aluminum was attached to the perimeter of the disk by laser welding. Since bonding of the aluminum foil between two cylinders was to be accomplished by ultrahigh vacuum diffusion bonding [8], the support ring facilitated the remote handling of the disks inside the diffusion bonding machine. Otherwise, the materials were used in the as-received state. 
The surfaces of the sapphire to be bonded and both sides of the $\mathrm{Al}$ foil were sputter cleaned with $1 \mathrm{keV} \mathrm{Xe} e^{+}$impinging at $15^{\circ}$ above the horizontal. Specimens were rotated during sputtering. The surface elemental composition was characterized using Auger electron spectroscopy. All surface contaminants thus measured, including the oxide layer on the metal, were removed to below the detection limit of the technique. Previous experience with $\mathrm{Al}$ shows that many hours of exposure are necessary to reform a contamination layer in the UHV environment $\left(<10^{-10}\right.$ torr). The specimens were stacked and a load of $10 \mathrm{MPa}$ applied. The specimens were heated to $600^{\circ} \mathrm{C}$ and held for $38 \mathrm{~h}$. Relatively long bonding times were required due to variations in the thickness of the $\mathrm{Al}$ foil which requires creep to bring the surfaces into contact and eliminate all void space.

Bend beams were cut from the diffusion bonds using diamond cutting. The beams had nominal dimensions of $3 \times 3 \times 40 \mathrm{~mm}$. To ensure that failure initiated in the metal foil rather than at a flaw in the ceramic, a thin notch was placed within the metal. The notch root diameter was $40 \mu \mathrm{m}$ and was $500 \mu \mathrm{m}$ deep. The beams were loaded in four-point loading with inner span of $10 \mathrm{~mm}$ and outer span of $30 \mathrm{~mm}$. Several beams were loaded to failure to characterize failure stresses.

Specimens examined with XTM were first characterized in the as-notched condition. The beam was then loaded until the first sign of non-linearity in the load versus cross-head displacement plot was observed. The mechanical test was interrupted, the specimen removed, and an XTM scan performed. The mechanical test was subsequently resumed to strain the beam further. This iterative sequence was continued for as long as was practical.

Ductile metals are opaque to the wavelengths of visible light. Hence, observations of the mechanisms of crack extension have not been possible in these materials. The advent of synchrotron-based XTM [9] has made it possible to determine the three-dimensional variations in density of specimens of several millimeters in dimension for low atomic number materials at resolutions approaching $1 \mu \mathrm{m}$. In performing the XTM scans, the X-rays from a synchrotron source (the 8pole wiggler beamline 4-2 at the Stanford Synchrotron Radiation Laboratory) were passed through a $\mathrm{Si}(220)$ monochromator to select $25 \mathrm{keV}$ photons. After passing through the specimen, the $\mathrm{X}$-rays struck a $\mathrm{CdWO}_{4}$ scintillator. The light emitted from the scintillator passed through magnifying optics and was collected by a CCD camera at a magnification sufficient to give the volume elements (voxels) in the reconstructed image the size $5.3 \mu \mathrm{m}$ on a side. Radiographs were collected at $0.5^{\circ}$ increments of sample rotation over a range of $180^{\circ}$. Reference images of the unobstructed $\mathrm{X}$-ray beam were acquired every 3 degrees to correct the radiographs for beam inhomogenieties, beam instabilities, and pixel-to-pixel gain variations in the CCD array. A threedimensional image, which represents the product of the pixel size and the absorption coefficient, was reconstructed as slices delineated by the rows of the CCD array using a filtered backprojection algorithm. Defects in the scintillator can give rise to bright or dark spots in radiographs which are not compensated for through normalization to the reference image. Such spots result in the appearance of bright or dark (usually dark) "rings" in the reconstructed slice. Most rings were removed using an interpolation algorithm on experimental sinograms. However some rings remained which can, in severe cases, give rise to contrast resembling voids, i.e., relatively low values of the absorption coefficient-thickness product. Such severe rings were found in the scans of the as-prepared sample and after the first deformation.

Locations of interfaces are delineated by pairs of bright and dark fringes in the XTM contrast. Although the origin of this fringe is currently not fully understood, the point of contrast reversal has been empirically shown to mark the interfaces. Voids, which have a relatively low values of the absorption coefficient-thickness product compared with the sapphire or aluminum are readily revealed by XTM. Voids exceeding two voxels in volume were identified and counted 
with an efficient, single-pass cluster labeling algorithim developed by Hoshen and Kopelman [10] and described in more detail elsewhere [11]. All void contrasts, including those from ring artifacts, are displayed in Figure 1. Although it is possible to follow the growth of isolated voids, this was not done in this initial study.

\section{RESULTS}

\section{As-prepared sample}

XTM revealed that the sample prepared in the 4-point bend geometry exhibited two dense interfaces between the aluminum and the sapphire. No resolvable voids were observed outside of three regions affected by ring defects. Figure 1a shows a rendering of the volume studied with XTM. The profile of the notch was extracted from this data and was used as input for finite element calculations to calculate the stress state of the sample.

\section{First deformation}

Figure $2 \mathrm{a}$ shows the load-displacement curve for the first in a series of three deformations. Loading was relaxed at the first indication of the onset of plasticity. XTM revealed four resolvable (size greater than 2 voxels) voids located at the interfaces between the metal and the sapphire. These voids were of volume between 3 and 7 voxels. Three of the voids were lenticular in nature. The fourth, and largest, had an aspect ratio (ratio of the radius of gyration normal to the interface to that in the plane of the interface) of about 1, i.e., the largest void was spherical. Figure $1 \mathrm{~b}$ show the rendered volume with voids (including those resulting from ring artifacts and those one voxel in size). Finite element modeling results for the maximum in triaxiality, maximum in tensile traction at the interface, and their locations relative to the notch root are shown in Table I.

Table I. Finite element modeling results for the maximum in triaxiality, maximum in tensile stress at the interface, and their locations relative to the notch root relative to the foil thickness.

\begin{tabular}{ccccc} 
Loading & $\sigma_{\mathrm{m}} / \sigma_{\mathrm{o}}$ & $\mathbf{X}_{\mathrm{m}} / \mathbf{h}$ & $\sigma_{\mathrm{yg}} / \sigma_{\mathrm{o}}$ & $\mathbf{X}_{\mathrm{yy}} / \mathbf{h}$ \\
\hline 1 & 4.1 & 2.3 & 4.5 & 2.3 \\
2 & 5.4 & 2.8 & 5.9 & 2.6 \\
\hline
\end{tabular}

Yield stress used in this calculation was $12.2 \mathrm{MPa}$, foil thickness was $50 \mu \mathrm{m}$, and notch depth was $630 \mu \mathrm{m}$.

\section{Second deformation}

Figure $2 b$ shows the load-displacement curve for the second deformation. XTM revealed 53 resolvable voids located at the interfaces between the metal and the sapphire. Figure 3 shows a slice through the volume revealing several voids at the interfaces. A common feature of is that they are all at the interfaces and voids are never seen to nucleate on opposite sides of the foil directly across from each other; they are usually staggered with respect to each other. Voids of size less than $\sim 30$ voxels are usually lenticular in shape. Between volumes of $30-100$ voxels, the 


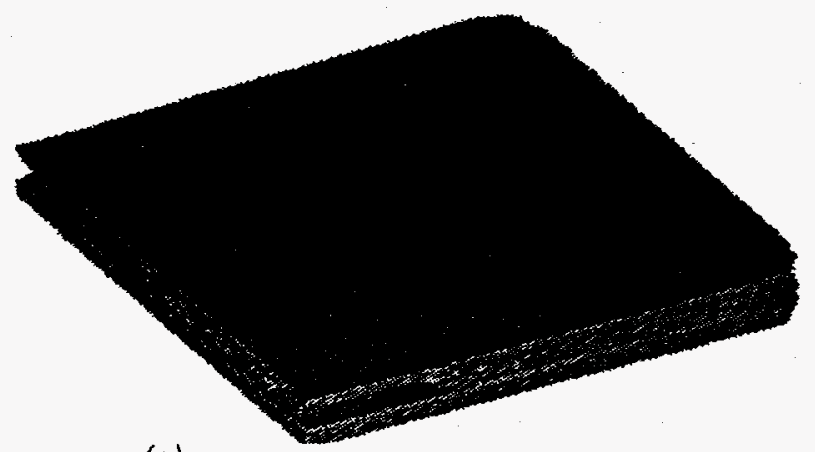

(a)
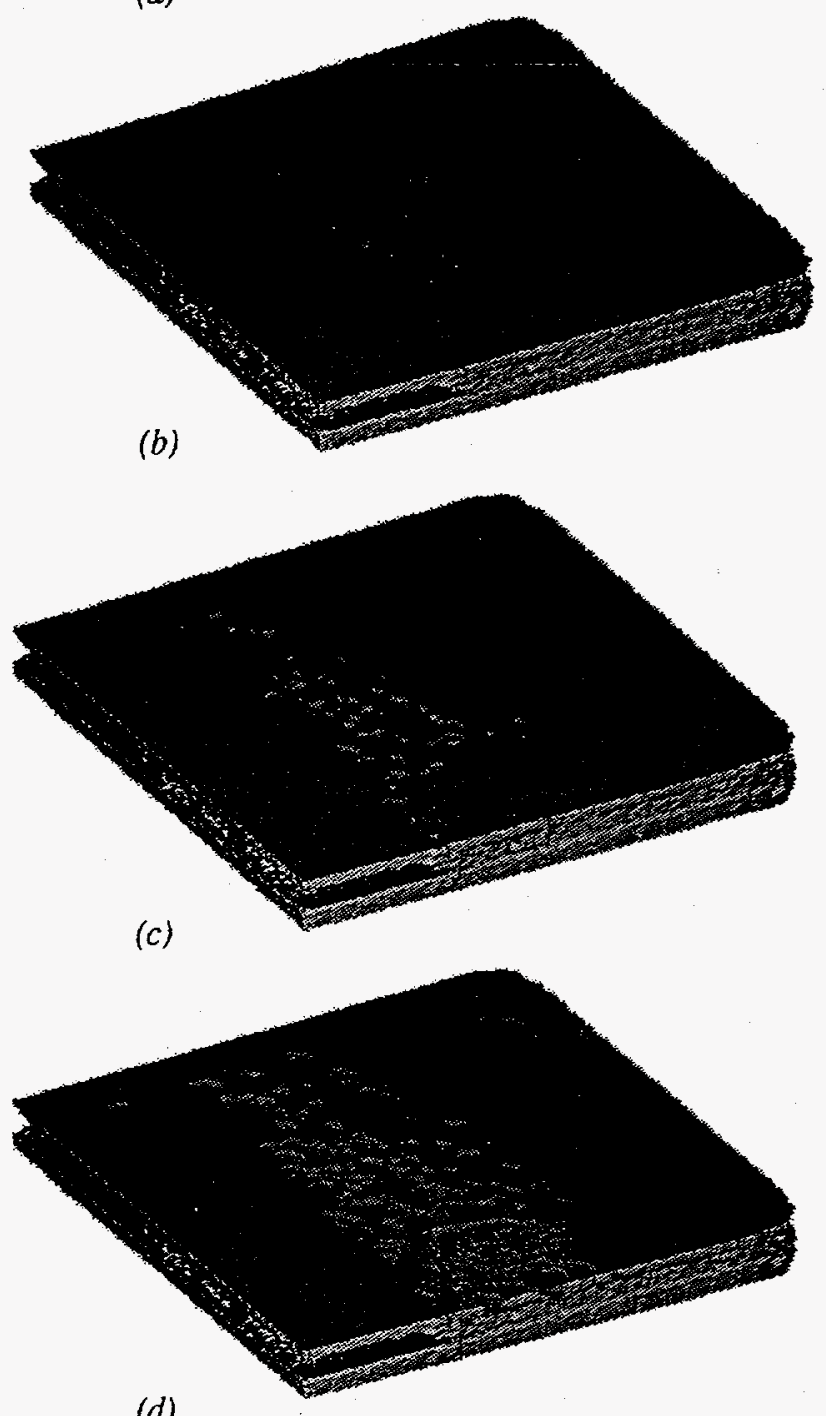

(d)

Fig. I. Rendering of (a) undeformed volume, (b) after first loading, (c) after second loading, (d) after third loading. Voids appear as lighter contrast features in the volume. 


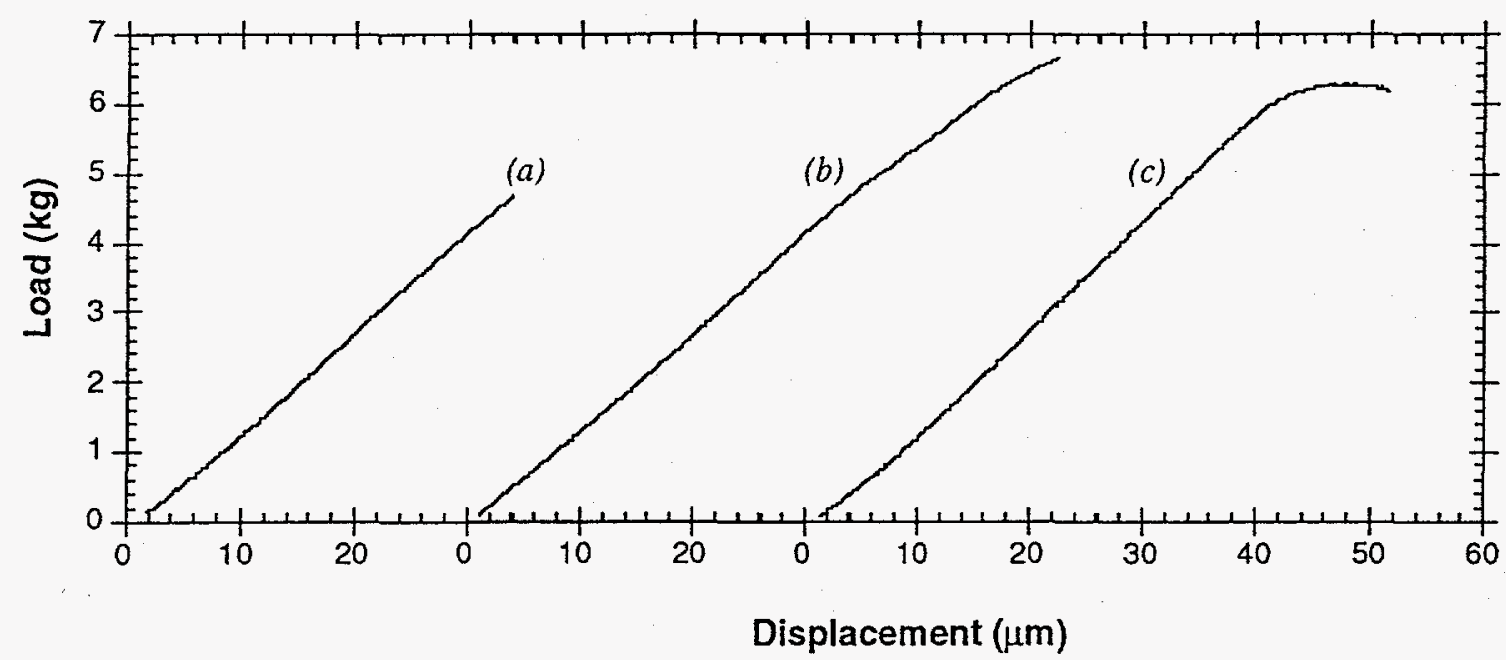

Fig. 2. Load as a function of cross-head displacement for (a) first loading, (b) second loading, (c) third loading.

aspect ratio grows to $\sim 0.6$. For volumes in excess of 100 voxels, the aspect ratio decreases to $\sim 0.2$. Figure $1 \mathrm{c}$ shows a rendering of the void distribution and illustrates the increase in the void population compared with the first deformation.

\section{Third deformation}

Figure $2 c$ shows the load-displacement curve for the third deformation. XTM revealed 131 resolvable voids located at the interfaces between the metal and the sapphire. While some small voids do take on a spheroidal shape, the general trend for the smallest and the largest voids is to have aspect ratios of $<0.2$. Voids in the range of $200-900$ voxels in volume tend to have aspect ratios approaching 0.4 . The void population has dramatically increased and the voids have spread ahead of the notch (Figure 1d).

\section{DISCUSSION}

XTM has been used to elucidate the mechanism of ductile rupture of a $50 \mu \mathrm{m}$ thick $\mathrm{Al}$ foil bonded between two sapphire cylinders subjected to Mode I loading. At the onset of plasticity, small lenticular voids form at each interface at a location consistent with the maxima in

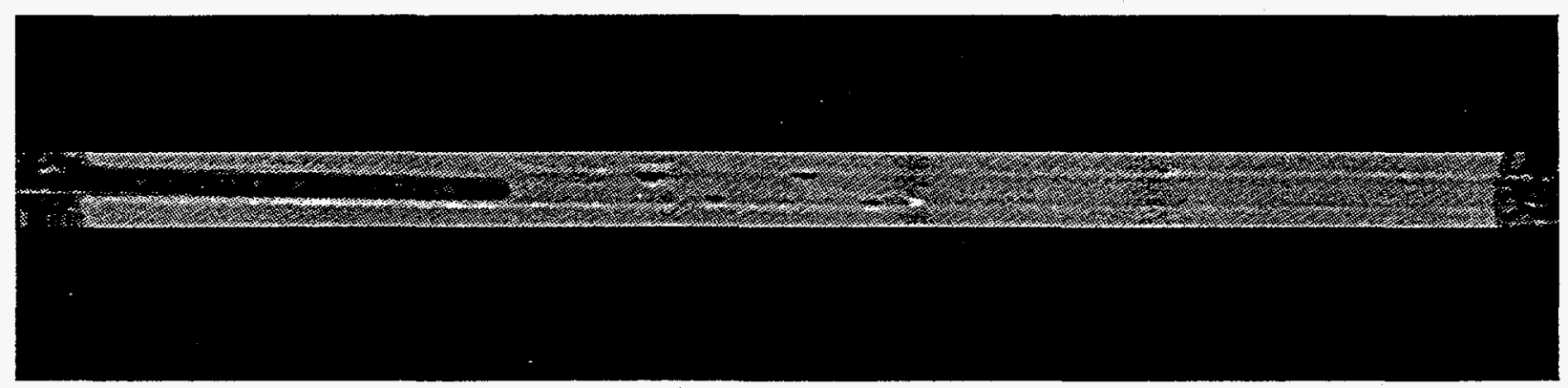

Fig. 3. Slice through volume perpendicular to notch after second deformation showing voids on both interfaces. 
triaxiality and tensile traction at the interface. As such, this work reveals that debonding plays an important role in the failure at the earliest stages of plasticity. Previous observations of rupture in this system revealed the presence of voiding on the fracture surfaces, e.g. see Ref. 1 and 2. However, the authors were only able to link the origin of some voids with the interfaces, i.e., the generalization of this observation to all voids was not clear. In this investigation, all voids were initially associated with an interface. Further, using conventional fractography, the mechanism of void nucleation and growth could not be revealed. The lenticular nature of these voids as revealed by XTM suggests that they may be formed by debonding and propagation of an interface crack rather than by nucleation and growth via dislocation agglomeration. The existence of debonds at interfaces in $\mathrm{Al}$ is consistent with observations in other systems, e.g., $\mathrm{Au}$ [3], $\mathrm{Nb}$ [4], and $\mathrm{Cu}$ [5], which debond but do not exhibit the extensive ductile dimpling found in Al. The observations of this work suggest that the tendency of a system to rupture in a ductile or brittle fashion may be controlled by the interplay of the interface bond strength and the yield strength of the metal. The formation of a void at an interface locally relaxes the constraint thus eliminating the possibility that a void will nucleate directly across the foil on the opposing interface. This increases the constraint nearby giving rise to the tendency of the voids to be staggered with respect to each other.

As deformation proceeds, voids of intermediate size tend to become spherical under the influence of the triaxial stress state which serves to relieve the constraint locally. It is reasonable to conclude that the maximum in the constraint then shifts to locations farther in advance of the notch root where more small debonds form. At high strains, spherical voids continue to grow until they interpenetrate which eventually leads to the formation of the ductile ligaments observed in fractographs. There appears to be a second class of voids that remain lenticular throughout the deformation. These seem to be lenticular voids that have grown past some perhaps critical size above which the tendency to become spherical is diminished.

\section{CONCLUSIONS}

Ultrahigh vacuum diffusion bonding has been used to make model specimens in the $\mathrm{Al} /$ sapphire system. The miocromechanics of failure for this system were observed by XTM. The primary findings are that (i) damage ahead of the notch initiates by interface debonding at a location coinciding with maxima in triaxiality and tensile traction at the interface, (ii) debonding occurs at the most early stages in the observation of plasticity, (iii) the debond expands for a limited distance, likely arresting due to crack tip blunting, (iv) this lenticular debond then becomes spherical with further strain and (v) intergrowth of the spherical voids leads to the typical ductile rupture fracture surfaces observed in this system. Future efforts to model this effect will need to include the debonds at the interface which alter the state of stress.

\section{ACKNOWLEDGEMENTS}

The authors gratefully acknowledge Professor R. H. Dauskardt for providing the mechanical testing equipment used in this investigation. This work performed under the auspices of U. S. Department of Energy and the Lawrence Livermore National Laboratory under contract No. W-7405-Eng-48. 


\section{REFERENCES}

1. B. J. Dalgleish, K. P. Trumble, and A. G. Evans, Acta Metall. 37, 1923 (1989).

2. W. E. King, G. H. Campbell, S. L. Stoner, and W. L. Wien, Cer. Eng. Sci. Proc., 15, 769 (1994).

3. I.E. Reimanis, B.J. Dalgleish, and A.G. Evans, Acta Metall. Mater. 39, 3133 (1991).

4. I.E. Reimanis, Scripta Metall. Mater. 27, 1729 (1992).

5. T.S. Oh, J. Rödel, R.M. Cannon, and R.O. Ritchie, Acta Metall. 36, 2083 (1988).

6. A. G. Varius, Z. Suo, and C. F. Shih, J. Mech. Phys. Solids 39, 963 (1991).

7. V. Tvergaard and J. W. Hutchinson, Phil. Mag. A 70, 641 (1994).

8. W. E. King, et al., Mat. Res. Soc. Symp. Proc. 314, 61 (1993).

9. J. H. Kinney and M. C. Nichols, Ann. Rev. Mater. Sci. 22, 121 (1992).

10. J. Hoshen and R. Kopelman, Phys. Rev. B,15 3438 (1976).

11. J. H. Kinney, N. E. Lane, and D. L. Haupt, J. Bone and Miner. Res. 10, 254 (1995). 